\title{
Sonicated Membrane Separation
}

\author{
BALÁZS LEMMER ${ }^{1}$, SZABOLCS KERTÉSZ2, GÁBOR KESZTHELYI-SZABÓ², \\ KERIME ÖZEL ${ }^{3}$, CECILIA HODÚR ${ }^{2 *}$
}

\begin{abstract}
Membrane separation processes are currently proven technologies in many areas. The main limitation of these processes is the accumulation of matter at the membrane surface which leads to two phenomena: concentration polarization and membrane fouling. According to the publications of numerous authors permeate flux could be increased by sonication. Our work focuses on separation of real broth by sonicated ultrafiltration. The broth was originated from hydrolysis of grounded corn-cob by xylanase enzyme. The filtration was carried out in a laboratory batch stirred cell with a sonication rod sonicator. In our work the effect of the stirring, the intensity of sonication and the membrane-transducer distance was studied on the efficiency of the ultrafiltration and on the quality of separated enzymes. Results reveal that xylanase enzyme can be effectively separated from real fermentation broth by ultrafiltration and enzymes keep their activity after the process. Enzyme activity tests show that low energy sonication is not harmful to the enzyme.
\end{abstract}

Keywords: enzyme, ultrafiltration, ultrasound, hydrolysis, xylanase

\section{Introduction}

Biomass energy has become a very crucial subject in relation to maintaining the sustainable energy without causing environmental pollution and reducing the effects of fossil fuels on the natural environment and human health (Kaplan, Aydin and Fidan, 2009). Biomass is a renewable energy resource with high potential that is derived from current or recently living organisms and is mostly plant-based. One of the most important implementations of biomass energy systems is the conversion of

\footnotetext{
${ }^{*}$ Corresponding author. E-mail: hodur@mk.u-szeged.hu

${ }^{1}$ Institute of Environmental Science and Technology, University of Szeged, Tisza Lajos krt. 103, H-6720 Szeged, Hungary

${ }^{2}$ Department of Process Engineering, Faculty of Engineering, University of Szeged, Moszkvai krt. 9, H-6725 Szeged, Hungary; E-mail: hodur@mk.u-szeged.hu

${ }^{3}$ Faculty of Engineering and Architecture, İzmir Kâtip Çelebi Üniversitesi, Balatçık Mahallesi Havaalanı Şosesi No:33/2 Balatçık 35620 Çiğli İzmir, Turkey
} 
lignocellulosic biomass to bioethanol. Bioethanol can be produced from numerous sources such as grain, molasses, sugar beets, sugarcane extract, corn and cellulose processed by biological sugar fermentation by microorganisms and continuously obtained by distillation (Hossain et al., 2008; Mills and Ecklund, 1987). Bioethanol has favourable combustion characteristic of alcohols, namely clean burning with high octane performance, which makes it an excellent melding component. With these characteristics of bioethanol, providing less combustion duration, it is considered to be a relatively good alternative to gasoline with high performance and efficiency in properly designed automotive systems (Kumar, Singh and Prasad, 2010; Berg, 2004).

\section{Theory}

Lignocellulose is a plant complex composed of cellulose microfibrils, hemicellulose and pectin in plant cell walls. Lignocellulosic biomass is the most abundant raw material in the world. Conversion of lignocellulose to bioethanol helps to increase the energy availability, decrease air pollution and diminish the atmospheric $\mathrm{CO}_{2}$ accumulation in a profitable and ecofriendly manner. Therefore, in the last two decades, extensive research has been carried out on this conversion, which consists of two processes: (i) hydrolysis of cellulose in the lignocellulosic materials to fermentable reducing sugars and (ii) fermentation of sugars to ethanol (Balat, 2007). The high cost of enzymes makes the process more uneconomical. For this reason, in our study, we used the membrane separation, which is considered to be the best enzyme recovering procedure (Prasad et al., 2007).

Being highly selective, energy-saving and low-cost, membrane separation takes an important place in bioethanol industry not only for starch-based but also for second generation technology of bioethanol. The main reason that leads to using the membrane separation systems is that it works with no chemicals added (Molina et al., 2008, Szélpál, Poser and Ábel, 2013). However, it should be remembered that membrane separation, despite being a very successful application in the production of bioethanol, still has to face some challenges. The most important among these is the fouling phenomena. This fouling can restrict the permeate rate and can essentially make the situation unsuitable for the application (Kang et al., 2014). 
Nowadays, there are many different procedures applied in membrane separation field. For instance, ultrasound-assisted membrane filtration, whose application has recently begun in membrane separation processes for the reason that the application of ultrasound in membrane systems can enhance the flux and prevents fouling on a large scale. The industrial use of ultrasound radiation is spreading continuously; US application for texture analysis to assess quality attributes is used by Kertész and Felföldi (2016) for cheese quality and maturity estimation.

The main experimental parameters that alter the ultrasonic filtration can be counted as external pressure, power density, cross-flow velocity, frequency and temperature (Muthukumaran et al., 2006; Hodúr et al., 2013). As Csoka et al. concluded the closer the horn is located to the bottom of the solid surface, the higher the efficiency in the horn type ultrasonic system (Csoka, Katekhaye and Gogate, 2011).

The aim of our work was to separate the enzymes from fermentation liquid produced from "Cobex" (corn cob grist) using the stirred batch filter and ultrasound-assisted membrane separation methods and later to analyse the enzyme activity under optimal temperature, pressure and $\mathrm{pH}$ conditions in order to make the bioethanol production process economically appropriate.

\section{Materials and Methods}

Membrane filtration. Separation was carried out with a stirred ultrafiltration batch device with a capacity of $400 \mathrm{~cm}^{3}$, equipped with a 40 $\mathrm{cm}^{2}$ polyethersulphone (PES) membrane with a cut-off value of $10 \mathrm{kDa}$. During filtration, the sample was mixed continuously with a magnetic stirrer, or an ultrasound processor (UP100H) was applied.

The filtration time and volume were measured, and the membrane permeability is expressed as the permeate flux through the membrane $(J)$, which was calculated as:

$$
J=\frac{d V}{d \tau} \frac{1}{A}=K_{M}(\Delta p-\Delta \pi)=\frac{\Delta p}{\eta \cdot R}
$$

where $J$ - the flux $\left[\mathrm{m}^{3} / \mathrm{m}^{2} \mathrm{~s}\right], A$ - surface of the filter $\left[\mathrm{m}^{2}\right], V$ - volume of the filtration $\left[\mathrm{m}^{3}\right], \tau$ - the time $[\mathrm{s}], K_{M}$ - permeability coefficient $\left[\mathrm{m}^{3} / \mathrm{m}^{2} \mathrm{sPa}\right], \Delta p$ - the pressure difference between the two sides of the membrane $[\mathrm{Pa}], \Delta \tau-$ the osmotic pressure $[\mathrm{Pa}], R$ - resistance of the process $[1 / \mathrm{m}]$. 
The total resistance consists of three parts: the resistance of the membrane $\left(R_{m}\right)$, the resistance of the irreversible flux decreasing mechanisms $\left(R_{i r r}\right)$, the resistance of reversible flux decreasing mechanisms $\left(R_{\text {rev }}\right)$ :

$$
R_{t}=R_{m}+R_{i r r}+R_{r e v}
$$

The $R_{m}$ was calculated from the flux of clean water through native membrane, the $R_{i r r}$ was calculated from the flux of clean water through rinsed membrane following the separation.

Samples for our work, fermentation liquid prepared from the hydrolysis of corn cob grist with the Xylanase enzyme was used as feed for membrane separation to analyse the enzyme recovery and followed enzyme activity.

Different separation methods were applied and the obtained permeates and concentrates were analysed after filtering. The different separation methods are shown in Table 1.

Table 1. Sonication and stirring parameters of samples

\begin{tabular}{|c|c|c|c|c|}
\hline \multirow{2}{*}{ samples } & horn distance & $\begin{array}{c}\text { sonication } \\
\text { intensity }\end{array}$ & stirring rpm \\
\cline { 3 - 5 } & {$[\mathrm{cm}]$} & {$[-]$} & {$\left[\mathrm{min}^{-1}\right]$} \\
\hline A1 & nostr 0.5US2cm & 2 & 0.5 & no \\
\hline A2 & nostr 0.5US3cm & 3 & 0.5 & no \\
\hline A3 & nostr 0.5US4cm & 4 & 0.5 & no \\
\hline B1 & str noUS & no & no & 350 \\
\hline B2 & str 0.5US3cm & 3 & 0.5 & 350 \\
\hline B3 & str 1US3cm & 3 & 1.0 & 350 \\
\hline
\end{tabular}

Fouling ratio $(F R R)$ was calculated with the following formula:

$$
\mathrm{FRR} \%=\left(1-\frac{\mathrm{J}_{\mathrm{w} 1}}{\mathrm{~J}_{\mathrm{w} 2}}\right) 100
$$

where $J\left[\mathrm{~m}^{3} / \mathrm{m}^{2} \mathrm{~s}\right]$, is the equilibrium flux at normal filtration, $J_{w 1}\left[\mathrm{~m}^{3} / \mathrm{m}^{2} \mathrm{~s}\right]$, is the water flux following the separation, $J_{w 2}\left[\mathrm{~m}^{3} / \mathrm{m}^{2} \mathrm{~s}\right]$, is the initial water flux.

Enzyme activity test was carried out in thermostatic laboratory stirred fermenters with capacity of $100 \mathrm{~cm}^{3}$. Permeate and concentrate samples from filtering experiments were used after diluting them to similar protein content, $\mathrm{pH}$ was set to 5.4. The substrate for the enzyme was $5 \mathrm{~g}$ Cobex corn-cob grist. The total volume of the samples was $100 \mathrm{~cm}^{3}$. Fermentation 
was kept for 2 days in $40{ }^{\circ} \mathrm{C}$. Samples were taken daily from the liquids and placed in freezer until measuring reducing sugar content. Sugar yield was proportional to enzyme activity.

Reducing sugar content was determined spectrophotometrically by the 3,5-dinitrosalicylic acid (DNSA) method. DNSA 3,5-(dinitrosalicylic acid) and $50 \mu \mathrm{l}$ of the sample were mixed and heated at $90{ }^{\circ} \mathrm{C}$ for 15 minutes. After cooling in water bath, the absorbance was measured at $575 \mathrm{~nm}$. This method tests for the presence of the free carbonyl group $(C=O)$, the socalled reducing sugars.

\section{Results}

The effect of the transducer distance from the membrane surface on the flux is presented in the Fig. 1. To summarize it can be said that the flux values under different transducer distances are quite similar but the rate of decreasing is a little bit different. This means that the components which cannot pass through the membrane and thus remain on the membrane surface cause a fall in flux values overall.

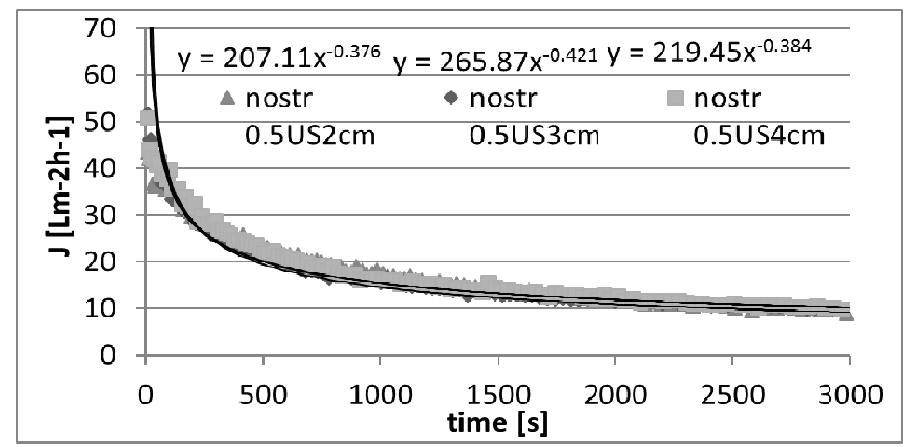

Fig. 1. Permeation flux as a function of time without stirring

There is no particularly noticeable difference between the samples in Fig. 1 but after the analysis of the measuring data and calculation of the resistances (Eq. 1), (Eq. 2), followed by the analysis of FRR (Eq. 3), valuable differences were observed (Fig. 2).

The rate of decreasing is expressed by the index of the fitted power equation and the fouling ratio in Fig. 2. The index expresses the flux rate reduction caused by total resistances, whereas $F R R$ reveals only decreasing irreversible resistance caused. Strong correlation is found between FRR\% 
and index of fitted power equations in Fig. 2; meaning both the total resistance and the irreversible resistance is the biggest at distance $3 \mathrm{~cm}$ compared to the other investigated distances.

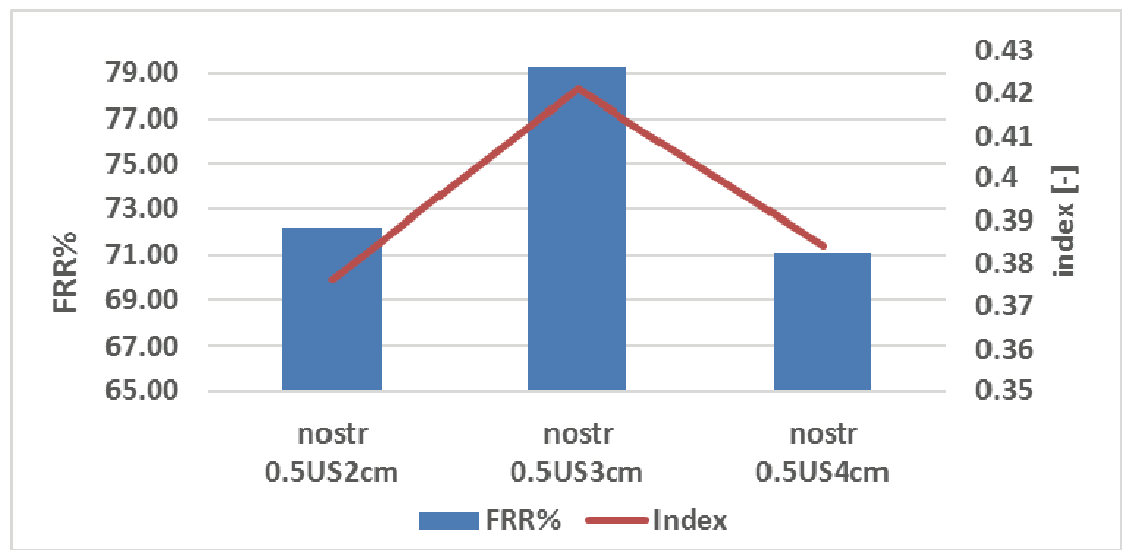

Fig. 2. Fouling ratio $(F R R \%)$ and index of fitted power equations

When we investigate the FRR calculated in Eq. 4. we can realise the importance of the distance between transducer and the membrane surface when there is no stirring effect.

This positive effect is caused by the ultrasound generated periodic mechanical motion. This periodic motion transfers energy into the solution and causes alterations in pressure leading to the creation of small rapidly growing bubbles. These bubbles are enlarged during the negative pressure cycles, finally collapsing violently which generates high pressures, temperatures and shear forces. This effect can cause the low $F R R \%$, since the medium size molecules are pushed through the pores by them. The investigation of the resistances enhanced the previous explanation (Fig. 3). The biggest total resistance is detected at $3 \mathrm{~cm}$ distance but there are no significant differences between the samples. Meanwhile the irreversible resistance is the biggest, the most unfavourable is at "nostr $0.5 \mathrm{US} 3 \mathrm{~cm}$ " samples; the reason for this is the previously mentioned ultrasound generated high pressure and shear force, since these are able to push the medium size molecules via pores, but some of these molecules are trapped by the tortuous path. 


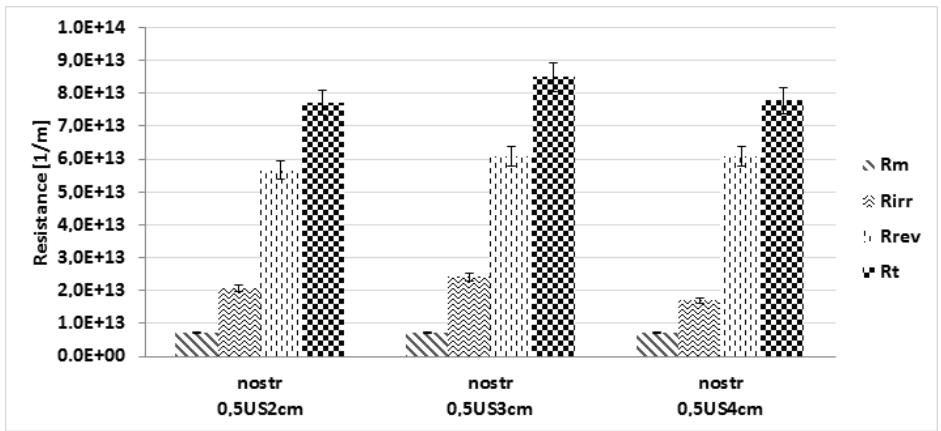

Fig. 3. Resistance values obtained without stirring

The sonication intensity refers to the ratio of time when the US processor is working on. The distance between the horn and the membrane surface was fixed as high as $3 \mathrm{~cm}$, the stirrer was used at $350 \mathrm{rpm}$ and the intensity of US was changed between 0.5 and 1.0, i.e. US energy was emitted only half time (0.5), or full time (1.0) during irradiation.

The data show (Fig. 4) that there is no significant difference between the samples regarding the flux as a function of the time; further data analyses are needed.

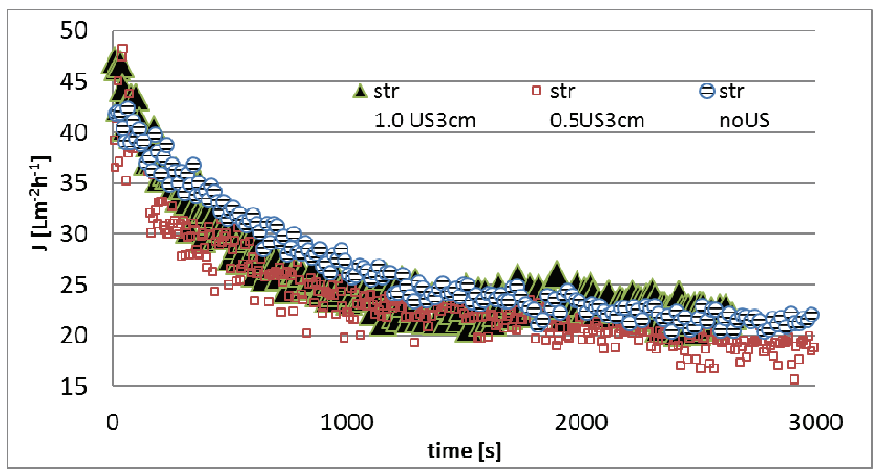

Fig. 4. Permeation flux as a function of time with stirring

Figure 5 shows an opposite tendency as shown in Fig. 2. The biggest index of fitted power equations was observed where the FRR is the smallest. The reason for this is that in this case (Fig. 5) ultrasonic treatment was accompanied by mixing at the same time. 


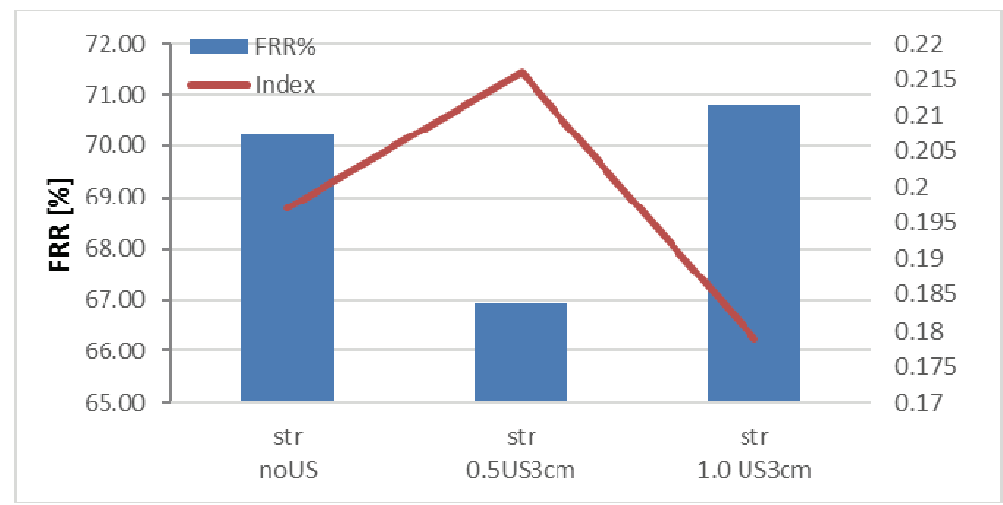

Fig. 5. Fouling ratio at different stirred samples

But when the resistance values are analysed in detail we can realize that there are differences between the irreversible and reversible ratios (Rirr/Rrev) (Fig. 6).

While the Rirr/Rrev ratio is the highest at "no stirring $0.5 \mathrm{US} 3 \mathrm{~cm}$ " samples, i.e. the irreversible resistance is the determinant, in the case of stirring samples the Rirr/Rrev ratio is the smallest at the "str0.5US3cm" sample. This ratio difference is the reason for the apparent contradiction.

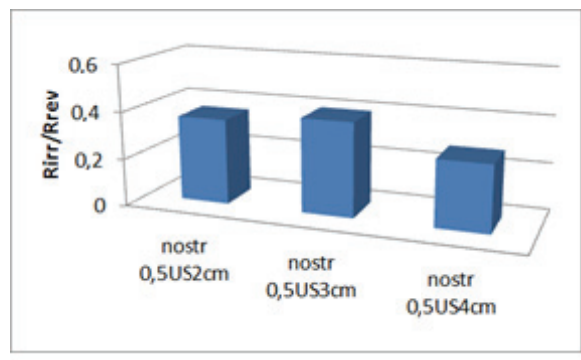

a)

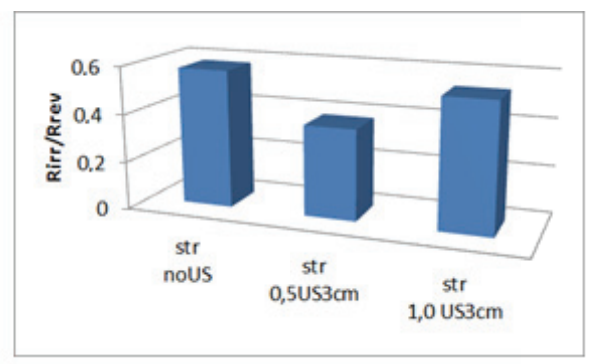

b)

Fig. 6. Ratios of the irreversible and reversible resistances a) without stirring, b) with stirring

Figure 7 illustrates different resistance values depending on different filtration applications. Overall, it can be clearly seen that the membrane resistance is stable in all methods as expected while irreversible and reversible resistance show a change in different applications of stirring apparatus and ultrasound with different intensity. 


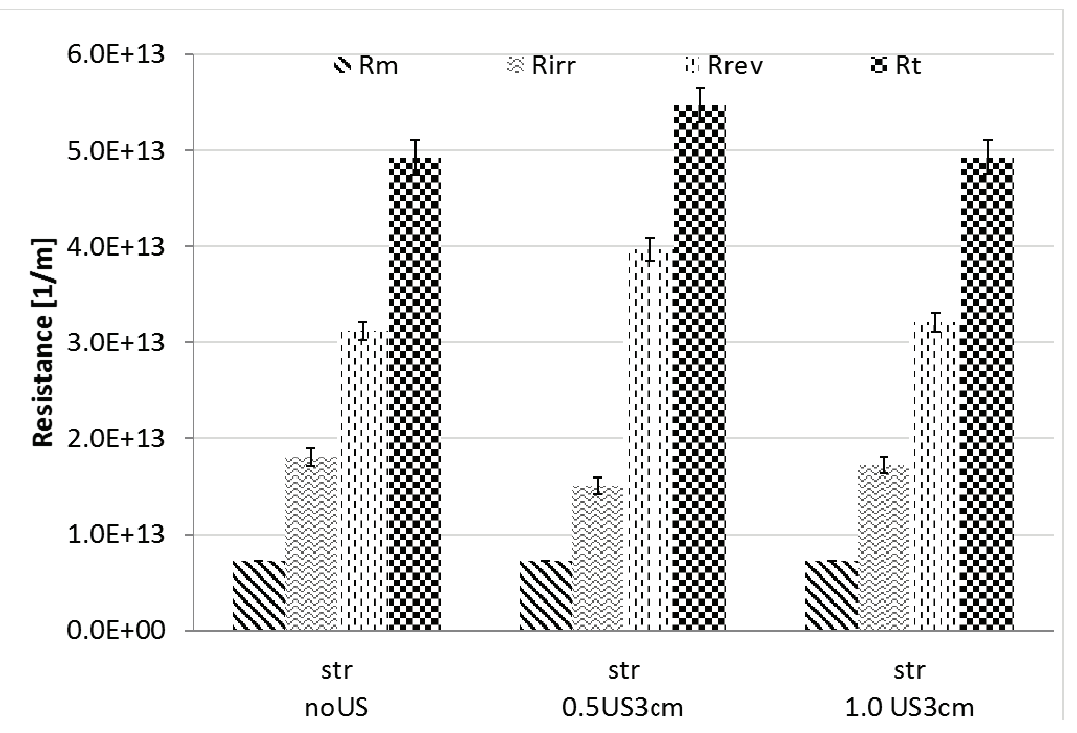

Fig. 7. Resistance values obtained without stirring

Effect of the processing on the enzyme activity is seen in Fig. 8, there is no growth in reducing sugar content when permeate is used for hydrolysis. The measured sugar content is a residual amount in the permeate phase from the previous fermentation. Significant sugar yield was detected when the concentrate was used. It means our theory is proved; neither the ultrafiltration, nor the ultrasound energy have any effect on the enzyme activity.

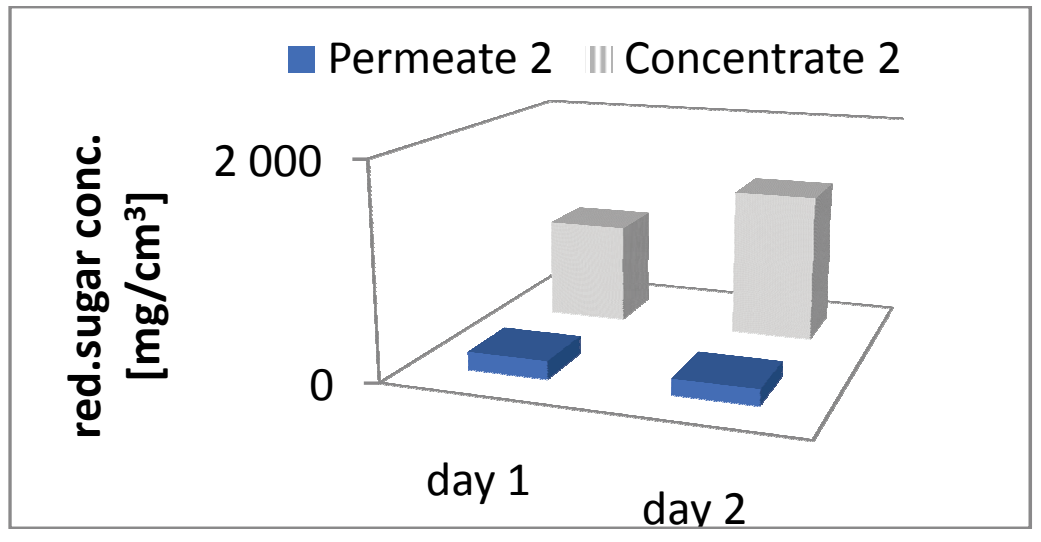

Fig. 8. Results of enzyme activity test 


\section{Conclusion}

The aim of our work was to separate xylanase enzyme from real fermentation broth by ultrafiltration and to study the effect on filtering behaviour of sonication and stirring. Results have revealed that xylanase enzyme can be effectively separated from real broth and low energy ultrasound is not injurious to the enzyme. Full intensity sonication can increase permeate flux when stirring is used but membrane fouling is more intensive. When stirring is not used and sonication intensity is 0.5, membrane-transducer distance has no significant effect either on permeation flux or resistances.

\section{Acknowledgments}

The authors are grateful for the financial support provided by the projects EFOP-3.6.2- 16-2017- 00010 - RING 2017 and National Office for Research, Development and Innovation - NKFIH, K115691.

\section{References}

Balat, M. (2007) Global bio-fuel processing and production trends. Energy Exploration $\mathcal{E}$ Exploitation, 25(3): 195-218.

Berg, C., World Fuel Ethanol Analysis and Outlook (2004) http://www.distill.com/ World-Fuel-Ethanol-A\&O-2004.html (accessed 13-11-2016).

Csoka, L., Katekhaye, S.N., Gogate P.R. (2011) Comparison of cavitational activity in different configurations of sonochemical reactors using model reaction supported with theoretical simulations. Chemical Engineering Journal, 178: 384-390.

Hodúr, C., Kertész, Sz., Szép, A., Keszthelyi-Szabó, G., László, Zs. (2013) Modeling of membrane separation and applying combined operations at biosystems. Progress in Agricultural Engineering Sciences, 9(1): 3-25.

Hossain, A.B.M.S., Saleh, A.A., Aishah, S., Boyce, A.N., Chowdhury, P.P., Naqiuddin M. (2008) Bioethanol production from agricultural waste biomass as a renewable bioenergy resource in biomaterials. 4th Kuala Lumpur International Conference on Biomedical Engineering 2008. 21:300-305.

Kang, Q., Appels, L., Baeyens, J., Dewil, R., Tan, T. (2014) Energy-efficient production of cassava-based bio-ethanol. Advances in Bioscience and Biotechnology, 5(12): 925-939.

Kaplan, M., Aydin, S., Fidan, M.S. (2009) Geleceğin Alternatif Enerji Kaynağ1 Biyoetanolün Önemi ve Sorgum Bitkisi. KSU Journal of Engineering Sciences, 12(1): 24-33.

Kertész, I., Felföldi, J. (2016) Comparison of sound velocity estimation and classification methods for ultrasonic testing of cheese. Progress in Agrucultural Engineering Sciences12(1): 51-62. 
Kumar, S., Singh, N., Prasad, R. (2010) Anhydrous ethanol: A renewable source of energy. Renewable and Sustainable Energy Reviews, 14(7): 1830-1844.

Mills, G.A., Ecklund, E.E. (1987) Alcohols as components of transportation fuels. Annu. Rev. Energy, 12: 47-80.

Molina, J., Vatai, Gy., Fogarassy, E., Bekassy-Molnar E. (2008) Application of membrane filtration to wastewater desalination. Progress in Agrucultural Engineering Sciences4(1): 77-92.

Muthukumaran, S., Kentis, S.E., Stevens, G. W., Ashokkumar, M. (2006) Application of ultrasound in membrane separation processes: a review. Reviews in Chemical Engineering 2(3): 155-194.

Prasad, S., Singh, A., Joshi, H.C. (2007) Ethanol as an alternative fuel from agricultural, industrial and urban residues. Resources, Conservation and Recycling, 50(1): 1-39.

Szélpál, Sz., Poser, O., Ábel, M. (2013) Enzyme recovery by membrane separation method from waste products of the food industry. Acta Technica Corviniensis Bulletin of Engineering, 6 (2): 149-154. 